\title{
Outcomes of an international multicenter registry on EUS-guided gallbladder drainage in patients at high risk for cholecystectomy*
}

\section{다)(i) $(5)$}

Authors

A.Y. Teoh ${ }^{1}$, Manuel Perez-Miranda ${ }^{2}$, Rastislav Kunda ${ }^{3}$, Sang Soo Lee ${ }^{4}$, Shayan Irani ${ }^{5}$, Paul Yeaton ${ }^{6}$, Siyu Sun ${ }^{7}$, Todd Huntley Baron ${ }^{8}$, Jong Ho Moon ${ }^{9}$, Bronte Holt ${ }^{10}$, Christopher J.L. Khor ${ }^{11}$, Rungsun Rerknimitr ${ }^{12}$, Amol Bapaye ${ }^{13}$, Shannon Melissa Chan ${ }^{1}$, Hyun Jong Choi ${ }^{9}$, Theodore William James ${ }^{8}$, Pradermchai Kongkam ${ }^{12}$, Yun Nah Lee ${ }^{9}$, Parth Parekh $^{14}$, Wiriyaporn Ridtitid ${ }^{12}$, Carlos Serna-Higuera ${ }^{2}$, Damien M.Y. Tan ${ }^{11}$, Raul Torres-Yuste ${ }^{2}$

Institutions

1 Department of Surgery, Prince of Wales Hospital, The Chinese University of Hong Kong, Shatin, Hong Kong

2 Department of Medicine, University Hospital Rio Hortega, Valladolid, Spain

3 Department of Surgical Gastroenterology, Aarhus University Hospital, Aarhus, Denmark

4 Division of Gastroenterology, Department of Internal Medicine, University of Ulsan College of Medicine, Asan Medical Center, Seoul, Korea

5 Digestive Disease Institute, Virginia Mason Medical Center, Seattle, Washington, United States

6 Department of Gastroenterology, Carilion Clinic, Roanoke, Virginia, United States

7 Endoscopy Center, Shengjing Hospital of China Medical University, Shenyang, China

8 Division of Gastroenterology and Hepatology, University of North Carolina at Chapel Hill, Chapel Hill, North Carolina, United States

9 Department of Internal Medicine, SoonChunHyang University College of Medicine, Bucheon Hospital, Bucheon/Seoul, Republic of Korea

10 Division of Gastroenterology, St Vincent's Hospital, Melbourne, Australia

11 Department of Gastroenterology and Hepatology, Singapore General Hospital, Singapore

12 Division of Gastroenterology, Department of Medicine, King Chulalongkorn Memorial Hospital, Bangkok

13 Shivanand Desai Center for Digestive Disorders, Deenanath Mangeshkar Hospital and Research Center, India

14 Eastern Virginia Medical School, Norfolk, Virginia, United States

submitted 23.2.2019

accepted after revision 10.4.2019
Bibliography

DOI https://doi.org/10.1055/a-0915-2098 |

Endoscopy International Open 2019; 07: E964-E973

(c) Georg Thieme Verlag KG Stuttgart · New York

elSSN 2196-9736

Corresponding author

Prof. Anthony Y.B. Teoh, Department of Surgery, Prince of

Wales Hospital, Shatin, New Territories, Hong Kong SAR

Fax: +852-35057974

anthonyteoh@surgery.cuhk.edu.hk

\section{ABSTRACT}

Background and study aims The aim of the current study was to review the outcomes of a large-scale international registry on endoscopic ultrasound-guided gallbladder drainage (EGBD) that encompasses different stent systems in patients who are at high-risk for cholecystectomy.

Patients and methods This was a retrospective international multicenter registry on EGBD created by 13 institutions around the world. Consecutive patients who received EGBD for several indications were included. Outcomes include technical and clinical success, unplanned procedural events (UPE), adverse events (AEs), mortality, recurrent cholecystitis and learning curve of the procedure.

Results Between June 2011 and November 2017, 379 patients were recruited to the study. Technical and clinical success were achieved in $95.3 \%$ and $90.8 \%$ of the patients, respectively. The 30 -day $\mathrm{AE}$ rate was $15.3 \%$ and 30 -day mortality was $9.2 \%$. UPEs were significantly more common in patients with EGBD performed for conversion of cholecystostomy and symptomatic gallstones $(P<0.001)$; and by endoscopists with experience of fewer than 25 procedures $(P=0.033)$. Both presence of clinical failure $(P=0.014$; RR $8.6995 \% \mathrm{Cl}[1.56-48.47])$ and endoscopist experience with fewer than 25 procedures $(P=0.002$; RR $4.6895 \% \mathrm{Cl}$ $[1.79-12.26])$ were significant predictors of 30 -day AEs.

\footnotetext{
* Meeting presentations: Digestive Disease Week 2018
} 
Presence of 30-day AEs was a significant predictor of mortality $(P<0.001$; RR $10395 \% \mathrm{Cl}[11.24-944.04])$.

Conclusion EGBD was associated with high success rates in this large-scale study. EGBD performed for indications other than acute cholecystitis was associated with higher UPEs. The number of cases required to gain competency with the technique by experienced interventional endosonographers was 25 procedures.

\section{Introduction}

Endoscopic ultrasound-guided gallbladder drainage (EGBD) was first described in 2007 [1]. Initially, the procedure was performed with plastic stents but they are prone to leakage or migration. Use of lumen-apposing stents (LAMS) and EUS-specific stents can potentially overcome these problems and the availability of these devices has dramatically changed the scope of endoscopic ultrasound-guided drainage procedures [2]. For gallbladder drainage, a number of studies have reported outcomes in small cohorts of patients and a meta-analysis reported pooled outcomes in 166 patients [3-8]. Outcomes from a large study cohort employing different stent systems, however, are lacking. Thus, the aim of the current study was to report the results of an international registry on EGBD employing different stent systems in patients who are at high risk for cholecystectomy. Furthermore, the learning curve and predictors to adverse events (AEs) and mortality of the procedure were addressed.

\section{Patients and methods}

This was a retrospective, international, multicenter registry on EGBD created by 13 institutions around the world. The institutional ethics committees of the respective hospitals approved the study protocol. Consecutive patients who received EGBD planned and attempted for symptomatic gallstones, acute cholecystitis or conversion of percutaneous cholecystostomy (PC) were included. The diagnosis of acute cholecystitis was made according to the revised Tokyo guidelines $[9,10]$. All patients were considered unfit for cholecystectomy if they satisfied one or more of the following criteria: Age $\geq 80$ years, American society of anesthesiology (ASA) grade 3 or above, age-adjusted Charlson score $\geq 4$ and/or Karnofsky score $<50$ [11-14]. The anesthesiologist and surgeons at the respective hospitals jointly made the decisions. Conversion of percutaneous cholecystostomy to EGBD was performed when the patient required long-term placement of cholecystostomy tubes [15]. Patients with the following conditions were excluded: suspected gangrene or perforation of the gallbladder, liver abscess or pancreatitis, altered anatomy of the upper gastrointestinal tract, pregnancy, decompensated liver cirrhosis, portal hypertension and/ or gastric varices, abnormal coagulation: international normalized ratio $>1.5$ and/or platelets $<50.000 / \mathrm{mm}^{3}$. Of the patients included in the current study, 88 were used in other submissions $[7,16-18]$.

\section{Types of stents used for EGBD}

EGBD was performed with a variety of LAMS and stents with antimigration designs $[2,19,20]$. The stents were further divided into single-step or multiple-step devices [5-8, 19, $21-25]$. The single-step device allows for single-step delivery of the stent without the need to change instruments for track dilation. This included the HOT AXIOS stent $(15 \times 10 \mathrm{~mm}$ or $10 \times 10 \mathrm{~mm}$ diameter, Boston Scientific, Marlborough, Massachusetts, United States) ( $\triangleright$ Fig. 1a). Multistep devices require track dilation with a cystotome and a 4- to 6-mm biliary balloon. Types of stents used included the SPAXUS stent $(10 \times 10 \mathrm{~mm}$ and $10 \times$ $16 \mathrm{~mm}$, Niti-S, Taewoong Medical, Korea) (> Fig.1b), the BONA-AL stent $(10 \mathrm{~mm} \times 4$ to $7 \mathrm{~cm}$ in length with 22 -mm external flares to prevent migration, Standard Sci Tech Inc., Seoul, Korea) ( Fig. 1c) and the Microtech stent $(10 \times 35 \mathrm{~mm}$ length, Nan Jing Co. Ltd., China) ( $\triangleright$ Fig. 1d). All procedures were performed by experienced interventional endosonographers.

\section{EUS-guided gallbladder drainage procedure}

The procedures were performed under conscious sedation or monitored anesthesia by dedicated endosonographers who were competent in performing advanced interventional EUS (including drainage of pancreatic fluid collections and bile ducts) in the respective hospitals. The gallbladder was identified by a linear echoendoscope and a suitable puncture site in the stomach or the duodenum without intervening blood vessels was located. One of the two methods were used for placement of stents ( $\triangleright$ Fig. 1). In the conventional method, the gallbladder was first punctured with a 19-gauge needle and the position was confirmed by aspiration of bile or contrast injection [7,19,21-23]. A 0.025 " or $0.035 "$ guide wire was passed through the needle and looped in the gallbladder. For centers using the single-step devices, the delivery system was inserted directly into the gallbladder with cautery. In those that use other stents, the needle track was dilated by a cystotome and a 4- to 6-mm biliary balloon. The delivery system of the stent was then inserted. For the direct puncture method, the gallbladder was directly punctured with the delivery system of the HOT AXIOS stent (Boston Scientific, Marlborough, Massachusetts, United States) [5, 6, 24, 25]. For both methods, after the delivery system of stents were inserted into the gallbladder, the distal flange of the stent was deployed under EUS guidance and the proximal flange deployed within the endoscope channel or under endoscopic guidance. Once deployed, the gallbladder was completely emptied by suction and irrigation until the effluent through the stent was clean. 


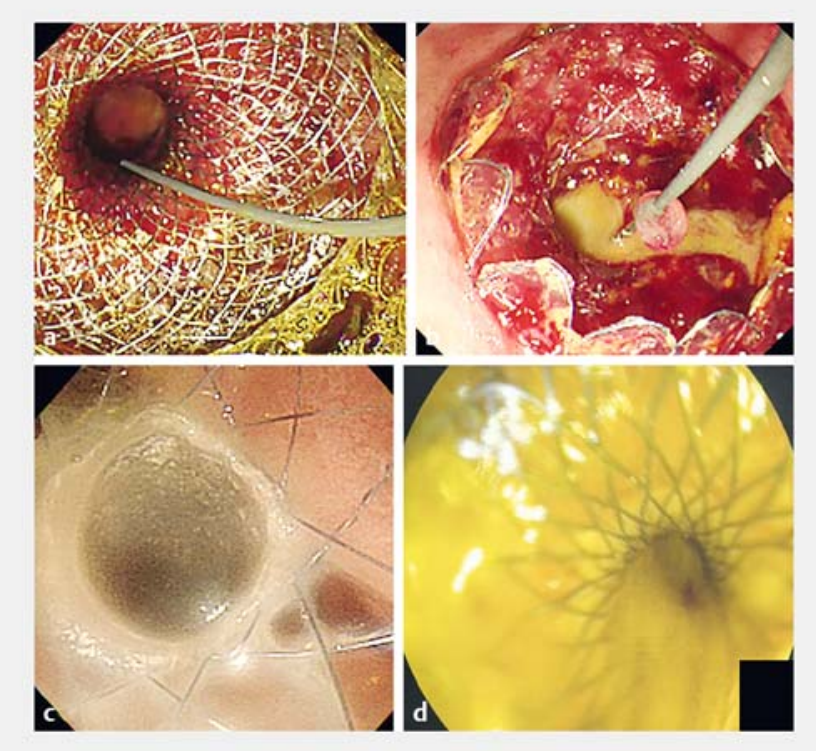

- Fig. 1 a EGBD performed with the AXIOS stent for conversion of a percutaneous cholecystostomy. $\mathbf{b}$ EGBD performed with the Spaxus stent. c EGBD performed with the BONA-AL stent. d EGBD performed with the Microtech stent.

\section{Post-procedural management}

Patients were monitored after the procedure and fluid diets were resumed the next day if they were afebrile and had presence of flatus or bowel output. Diets were then stepped-up to regular diet if they tolerated fluid.

\section{Follow-up management}

The stents were either placed permanently for long-term drainage or a scheduled peroral cholecystoscopy was performed at 1 to 3 months for gallstone retrieval $[20,26]$. In centers where a follow-up peroral cholecystoscopy was performed, it was done under carbon dioxide insufflation with a $9.8-\mathrm{mm}$ magnifying endoscope equipped with water-jet irrigation (GIF-H290Z, Olympus, Tokyo, Japan). Gallstones were retrieved with standard ERCP devices and the stents were removed when the gallbladder were stone free.

\section{Outcome parameters}

Outcomes reviewed included technical and clinical success, unplanned procedural events (UPEs), 30-day AEs, 30-day mortality, recurrence rates and learning curve of the procedure. Technical success was defined as successful placement of a stent with immediate drainage of bile. Clinical success was defined as improvement in clinical symptoms after placement of stents. UPE were defined as any deviations of the procedure from the planned procedural steps. These events include dislodged guidewires or misdeployment of the stents, where subsequent proper placement of the stent may not lead to any clinical sequalae. Severity of AEs was graded according to the lexicon of endoscopic AEs [27]. To quantify the number of procedures required to gain competency, outcomes of EGBD in endoscopists with $<25$ and $\geq 25$ procedures were compared.

\section{Statistical analyses}

Statistical analyses were performed using SPSS 20.0 statistical software (SPSS, Chicago, Illinois, United States). Comparisons were made by Chi-squared or Fisher exact test for categorical data, Wilcoxon signed-rank test for non-parametric continuous data. Predictors of UPEs, AEs and mortality were analyzed by logistic regression analysis using the enter method. A two-sided $P$ value $<0.05$ was considered significant.

\section{Results}

Between June 2011 and November 2017, 379 patients were recruited to the study. Background demographics are shown in - Table 1. Indications for EUS-guided gallbladder drainage were acute cholecystitis (86.3\%), conversion of cholecystostomy ( $9 \%)$ and symptomatic gallstones (4.7\%). The majority of patients had EGBD performed with the AXIOS stent (75.2\%), followed by BONA-AL (12.1\%), Microtech (7.7\%) and SPAXUS $(2.4 \%)$ stents. Technical and clinical success were achieved in $95.3 \%$ and $90.8 \%$ of patients, respectively. Mean (S.D.) procedural time was 60 minutes (58.4). UPEs occurred in $9.2 \%$ of patients. The mean (S.D.) hospital stay was 9.0 days (8.3) and follow-up duration was 433.6 days (505.1). The 30-day AE rate was $15.3 \%$ and the 30 -day mortality rates was $9.2 \%$. Types of 30-day AEs are shown in - Supplementary Table 1. Nine patients in the cohort $(2.4 \%)$ suffered from recurrent cholecystitis.

The study cohort was then divided into several subgroups for analysis. We first compared outcomes of patients with and without UPEs ( $\triangleright$ Table 2 ). In patients with UPEs, significantly more had EGBD performed for conversion of cholecystostomy and symptomatic gallstones $(P<0.001)$. Furthermore, endoscopists with experience with fewer than 25 procedures had significantly more UPEs $(P=0.033)$. Presence of UPEs also resulted in significantly longer hospital stay $(P=0.002)$ while no difference in 30-day AEs and mortality was observed.

Outcomes of procedures performed by endoscopists with experience of $<25$ versus $\geq 25$ EGBD procedures were then compared ( $\triangleright$ Table 3 ). Endoscopists who had done fewer than 25 of the procedures had significantly more procedures that were longer than 30 minutes $(P=0.006)$, more UPEs $(P=0.012)$ and more 30-day AEs $(P=0.031)$. When comparing outcomes of different stent systems ( $\triangleright$ Supplementary Table 2 ), significant differences were present in occurrence of UPEs $(P=0.028)$, percentage of procedures performed by endoscopist with fewer than 25 procedures $(P<0.001)$ and the 30 -day AEs.

Multivariate analyses to assess for predictors of 30-day AEs ( $\triangleright$ Table 4$)$ and mortality ( $>$ Table 5 ) were then performed. Both presence of clinical failure $(P=0.014$; RR $8.6995 \% \mathrm{Cl}$ [1.56-48.47]) and procedure performed by endoscopists with experience with fewer than 25 procedures $(P=0.002$; RR 4.68 $95 \% \mathrm{Cl}[1.79-12.26])$ were significant predictors of 30 -day AEs. While only presence of 30-day AEs was a significant predictor of mortality ( $P<0.001$; RR $10395 \% \mathrm{Cl}$ [11.24-944.04]). 
- Table 1 Background demographics and outcomes.

\begin{tabular}{|l|c|}
\hline & EGBD \\
\hline Age (years) & $\mathbf{N}=\mathbf{3 7 9}$ \\
\hline Sex (M/F) & $19.6(15.0)$ \\
\hline Mean (S.D.) age-adjusted Charlson comorbidity index & $5.9(3.1)$ \\
\hline Indication & \\
\hline - Acute cholecystitis & $327(86.3 \%)$ \\
\hline - Conversion of cholecystostomy & $34(9 \%)$ \\
\hline - Symptomatic gallstones & $18(4.7 \%)$ \\
\hline Types of stents used & $285(75.2 \%)$ \\
\hline - AXIOS & $56(14.8 \%)$ \\
\hline - Bona - AL & $29(7.7 \%)$ \\
\hline - Microtech & $9(2.4 \%)$ \\
\hline - SPAXUS & \\
\hline EGBD, endoscopic ultrasound-guided gallbladder drainage & \\
\hline
\end{tabular}

Table 2 Comparison of patient outcomes in those with or without unplanned procedural events.

\begin{tabular}{|c|c|c|c|}
\hline & $\begin{array}{l}\text { With UPE } \\
N=35\end{array}$ & $\begin{array}{l}\text { Without UPE } \\
N=344\end{array}$ & $P$ value \\
\hline Age-adjusted Charlson comorbidity index $>6(\%)$ & $11(32.4)$ & $101(29.4)$ & 1 \\
\hline \multicolumn{4}{|l|}{ Indication for EGBD (\%) } \\
\hline - Acute cholecystitis & $22(62.9)$ & $305(88.7)$ & \multirow[t]{3}{*}{$<0.001^{1}$} \\
\hline - Conversion of cholecystostomy & $8(22.9)$ & $26(7.6)$ & \\
\hline - Symptomatic gallstones & $5(14.3)$ & $13(3.8)$ & \\
\hline \multicolumn{4}{|l|}{ Severity of acute cholecystitis (TG grading) (\%) } \\
\hline . 1 & $3(20)$ & $81(39.5)$ & \multirow[t]{3}{*}{0.324} \\
\hline - 2 & $10(66.7)$ & $103(50.2)$ & \\
\hline .3 & $2(13.3)$ & $21(10.2)$ & \\
\hline \multicolumn{4}{|l|}{ Stent type (\%) } \\
\hline - AXIOS & $24(68.6)$ & $261(75.9)$ & \multirow[t]{4}{*}{$0.028^{1}$} \\
\hline - SPAXUS & $0(0)$ & $9(2.6)$ & \\
\hline - Bona-AL & $4(11.4)$ & $52(15.1)$ & \\
\hline - Microtech & $7(20)$ & $22(6.4)$ & \\
\hline \multicolumn{4}{|l|}{ Endoscopist experience (\%) } \\
\hline - $<25$ & $23(65.7)$ & $148(43)$ & \multirow[t]{3}{*}{$0.033^{1}$} \\
\hline - $25-50$ & $10(28.6)$ & $150(43.6)$ & \\
\hline - $>50$ & $2(5.7)$ & $46(13.4)$ & \\
\hline 30-day adverse events (\%) & $8(22.9)$ & $50(14.5)$ & 0.216 \\
\hline 30-day mortality (\%) & $4(11.4)$ & $31(9)$ & 0.549 \\
\hline Hospital stay (SD) (days) & $13.5(9.1)$ & $8.5(8.0)$ & $0.002^{1}$ \\
\hline
\end{tabular}


- Table 3 Comparison of patient outcomes in those procedures performed by endoscopist with experience $<25$ versus $\geq 25$ EGBD procedures.

\begin{tabular}{|c|c|c|c|}
\hline & $\begin{array}{l}<25 \text { procedures } \\
N=171\end{array}$ & $\begin{array}{l}\geq 25 \text { procedures } \\
N=208\end{array}$ & $P$ value \\
\hline \multicolumn{4}{|c|}{ Procedural time (\%) } \\
\hline - $\leq 30$ minutes & $32(33)$ & $79(50.6)$ & \multirow[t]{2}{*}{$0.006^{1}$} \\
\hline - $>30$ minutes & $65(67)$ & $50.6(49.4)$ & \\
\hline \multicolumn{4}{|c|}{ Technical success (\%) } \\
\hline - Yes & $161(94.2)$ & 185 (88.9) & \multirow[t]{2}{*}{0.098} \\
\hline - No & $10(5.8)$ & $23(11.1)$ & \\
\hline \multicolumn{4}{|c|}{ Clinical success (\%) } \\
\hline - Yes & $153(89.5)$ & $197(94.7)$ & \multirow[t]{2}{*}{0.079} \\
\hline - No & $18(10.5)$ & $11(5.3)$ & \\
\hline \multicolumn{4}{|c|}{ Unplanned procedural events (\%) } \\
\hline - Yes & $23(13.5)$ & $12(5.8)$ & \multirow[t]{2}{*}{$0.012^{1}$} \\
\hline - No & $148(86.5)$ & $196(94.2)$ & \\
\hline \multicolumn{4}{|c|}{ 30-day adverse events (\%) } \\
\hline - Yes & $34(19.2)$ & $24(11.5)$ & \multirow[t]{2}{*}{$0.031^{1}$} \\
\hline - No & $137(80.1)$ & $184(88.5)$ & \\
\hline \multicolumn{4}{|c|}{ 30-day mortality (\%) } \\
\hline - Yes & $18(10.5)$ & $17(8.2)$ & \multirow[t]{2}{*}{0.478} \\
\hline - No & $153(89.5)$ & $191(91.8)$ & \\
\hline
\end{tabular}

\section{Discussion}

The current study is the first large-scale study reporting outcomes of EGBD using different stent systems for gallbladder drainage in patients at high risk for cholecystectomy. Overall, the procedure is associated with high technical and clinical success rates with acceptable AE rates. On subgroup analysis, UPEs were significantly higher in EGBD performed for indications other than acute cholecystitis, by endoscopist with experience with fewer than 25 procedures and resulted in longer hospital stay. Furthermore, significantly more procedures performed by endoscopists with experience with fewer than 25 procedures had longer duration, UPEs, and 30-day AEs. On multivariate analysis, presence of clinical failure and endoscopist experience with fewer than 25 procedures were significant predictors of AEs while only presence of 30-day AEs was a significant predictor of mortality.

Findings from the current study are interesting in several ways. First, rates of UPE were higher in EGBD performed for indications other than acute cholecystitis. This is consistent with the traditional surgical dogma that "not all gallbladders are the same" when performing cholecystectomy. In patients with acute cholecystitis, the gallbladder is frequently very distended, making it an easy target for puncture and drainage. In pa- tients with previous cholecystostomy, however, the gallbladder may be contracted and fibrotic. Even with use of contrast injection through the cholecystostomy tube, the extent of gallbladder distension may be limited. Thus, a contracted and fibrotic gallbladder is difficult to puncture and drain. Presence of gallstones in a small gallbladder may further hinder placement of a large-diameter metal stent for effective EGBD.

In addition, the endoscopist's experience is an important parameter for development of UPEs and 30-day AEs. In the literature, learning curves for performance of any interventional EUS procedures are poorly defined and the number of procedures required to gain competency in EGBD were not previously published. The number used in this study was referenced from the numbers previously reported for EUS-guided drainage of pancreatic fluid collections. For pancreatic fluid collections, two studies have examined the impact on outcomes of increasing experience with the procedure $[28,29]$. One study noted better resolution rates and days to resolution after the first 20 procedures [28]. In another study, however, the procedural time was found to be significantly shorter after the first 25 procedures [29]. In a more recent guideline, it was suggested that for endosonographers experienced in ERCP, performance of five to 10 procedures is required to gain competency with EUS-guided drainage of pancreatic fluid collections [30]. In 
- Table 4 Predictors of 30-day adverse events by multivariate analysis.

\begin{tabular}{|l|l|l|}
\hline Parameter & P value & RR (95\% CI) \\
\hline Age $>75$ years old & 0.683 & $0.81(0.30-2.20)$ \\
\hline Sex & 0.123 & $0.33(0.08-1.35)$ \\
\hline Age adjusted Charlson comorbidity index $>6$ & 0.963 & $1.02(0.39-2.69)$ \\
\hline Technical failure & 0.491 & $0.43(0.38-4.79)$ \\
\hline Clinical failure & 0.014 & $8.69(1.56-48.47)$ \\
\hline Unplanned procedural events & 0.123 & $0.33(0.08-1.35)$ \\
\hline Endoscopist experience $<25$ procedures & 0.002 & $4.68(1.79-12.26)$ \\
\hline RR, relative risk; Cl, confidence interval & & \\
\hline
\end{tabular}

- Table 5 Predictors of 30-day mortality by multivariate analysis.

\begin{tabular}{|l|c|c|}
\hline Parameter & P value & RR (95\% Cl) \\
\hline Age $>$ 75 years & 0.986 & $0.98(0.16-5.98)$ \\
\hline Age-adjusted Charlson comorbidity index>6 & 0.278 & $0.28(0.03-2.79)$ \\
\hline Sex & 0.654 & $1.55(0.23-10.72)$ \\
\hline Technical failure & 0.312 & $7.81(0.15-421.11)$ \\
\hline Clinical failure & 0.056 & $13.38(0.93-192.30)$ \\
\hline Unplanned procedural events & 0.453 & $2.98(0.17-51.38)$ \\
\hline Endoscopist experience $<25$ procedures & 0.061 & $0.12(0.013-1.10)$ \\
\hline 30-day adverse events & $<0.001$ & $103(11.24-944.04)$ \\
\hline RR, relative risk; Cl, confidence interval & & \\
\hline
\end{tabular}

contrast to pancreatic fluid collections, the gallbladder is a freely mobile organ and the margin of error for EGBD is considerably larger. Thus, those attempting EGBD should only do so when they are familiar with other types of EUS drainage procedures that incur similar basic procedural steps including needle puncture, track dilation, and stent insertion. Furthermore, endosonographers performing EGBD in this study were already skilled at performing other types of interventional EUS procedures. Thus, their learning curves would be different than those of endoscopists just starting to perform interventional EUS. The number of procedures required to gain competency in this manuscript will need to be validated in future prospective studies.

EGBD is gaining popularity as an alternative to gallbladder drainage in patients at high risk for cholecystectomy worldwide ( Table 6). In a pooled analysis including 166 cases, the overall technical success rate, clinical success rate, and frequency of AEs were $95.8 \%, 93.4 \%$, and $12.0 \%$, respectively [8]. A number of retrospective comparative studies have shown that compared to percutaneous cholecystostomy, EGBD is associated with fewer AEs, shorter hospital stays, and fewer reinterventions and unplanned readmissions [3-7]. This is mainly due to cholecystostomy tube-related AEs, including dislodgement, migra- tion, obstruction, and peri-tubal leakage. Furthermore, longterm outcomes of EGBD appear to be favorable, with a late AE rate of $7.1 \%$ and a rate of recurrent cholecystitis of $3.2 \%$ in one study [17]. Tose rates are comparable to the $2.4 \%$ rate of recurrent cholecystitis reported in this study.

There are a number of limitations to the current study. First, the retrospective nature makes the data prone to selection and lead time bias. Second, the comparison of outcomes of different stent systems needs to be interpreted with caution. These outcomes could be influenced by the endoscopist's experience and other factors, and may not be solely attributable to the properties of the stent systems. Finally, this study did not address how EGBD compared to other drainage procedures and no conclusion could be drawn about superiority or inferiority. An ongoing randomized controlled trial (NCT02212717) comparing EGBD versus percutaneous cholecystostomy is expected to provide more evidence to the procedures. 

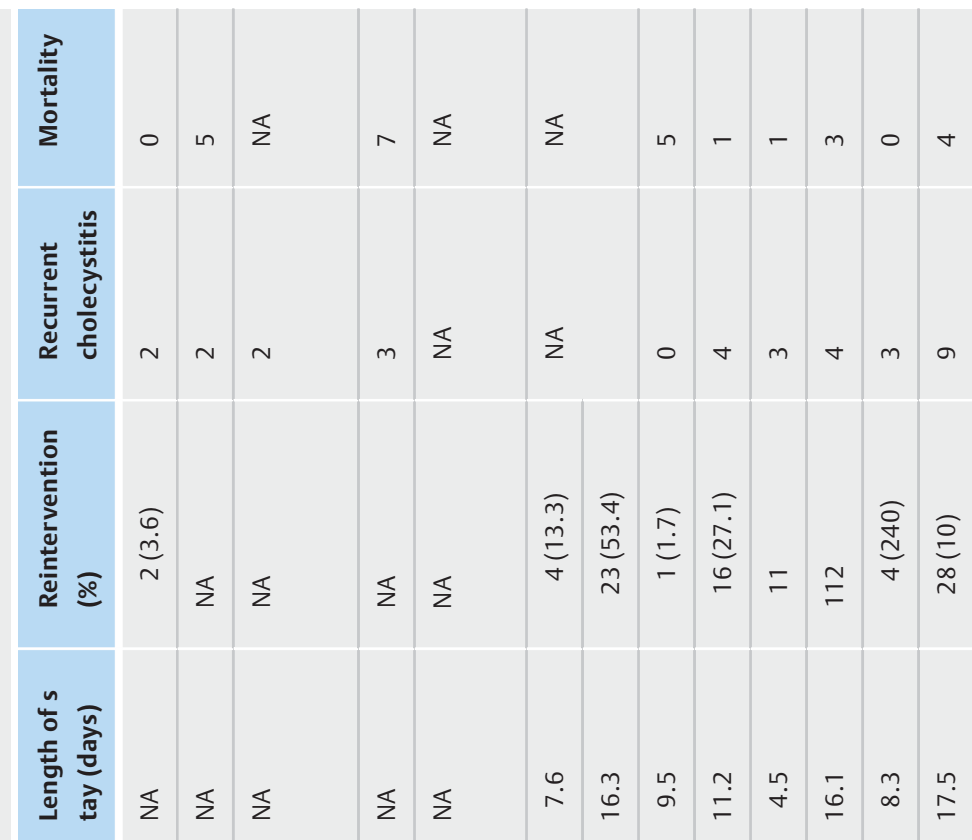

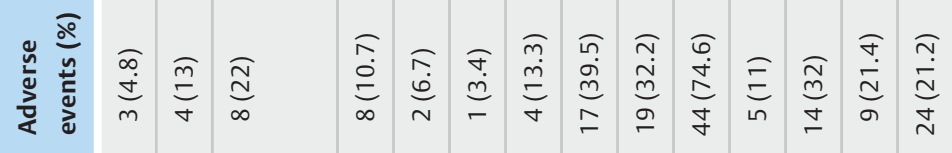

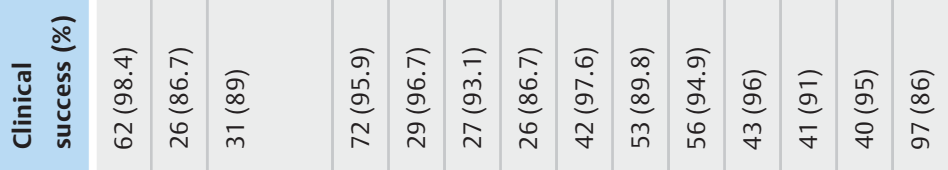

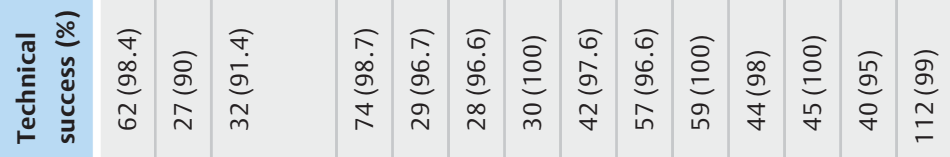

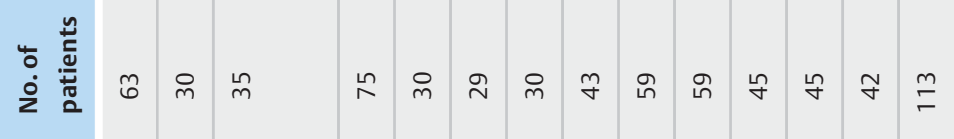

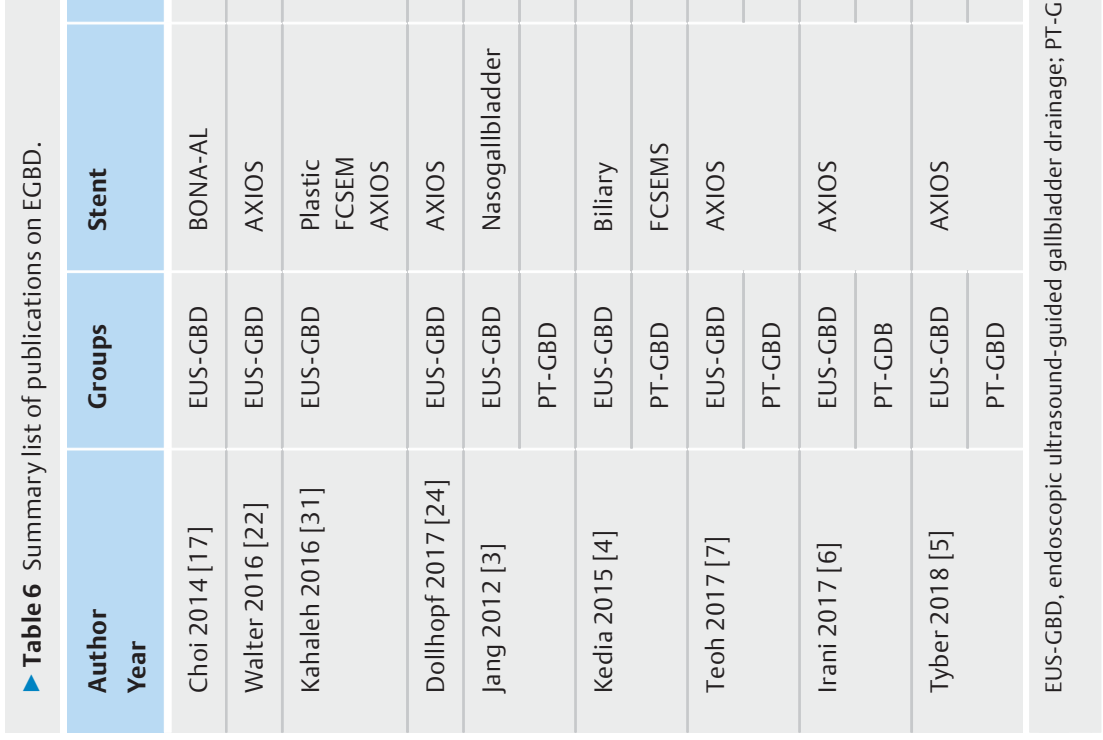




\section{Conclusion}

In conclusion, EGBD with different stent systems is associated with high technical and clinical success rates in this large-scale study. EGBD performed for indications other than acute cholecystitis was associated with higher UPEs. Endoscopist experience is an important parameter for outcomes and the number of cases required to gain competency with the technique is approximately 25 procedures. Clinical failure and endoscopist experience were predictors of 30-day AEs and the presence of 30day AEs was a predictor of mortality.

\section{Competing interests}

Dr. Teoh is a consultant for Boston Scientific, Cook, Taewoong, Cook and Microtech Medical Corporations. Dr. Baron is a consultant for Boston Scientific Medical Corporation. Dr. Moon is a consultant for Taewoong Medical Corporation. Dr. Siyu is a consultant for Microtech Medical Corporation. Dr. Kunda is a consultant for Boston Scientific, Omega Medical Imaging, and BCM Korea.

\section{References}

[1] Baron TH, Topazian MD. Endoscopic transduodenal drainage of the gallbladder: implications for endoluminal treatment of gallbladder disease. Gastrointestinal endoscopy 2007; 65: 735 - 737

[2] Teoh AY, Ng EK, Chan SM et al. Ex vivo comparison of the lumen-apposing properties of EUS-specific stents (with video). Gastrointest Endosc 2016; 84: 62-68

[3] Jang JW, Lee SS, Song T] et al. Endoscopic ultrasound-guided transmural and percutaneous transhepatic gallbladder drainage are comparable for acute cholecystitis. Gastroenterology 2012; 142: 805 811

[4] Kedia P, Sharaiha RZ, Kumta NA et al. Endoscopic gallbladder drainage compared with percutaneous drainage. Gastrointest Endosc 2015; 82: $1031-1036$

[5] Tyberg A, Saumoy M, Sequeiros EV et al. EUS-guided Versus Percutaneous Gallbladder Drainage: Isn't It Time to Convert? J Clin Gastroenterol 2018; 52: 79-84

[6] Irani S, Ngamruengphong S, Teoh A et al. Similar efficacies of endoscopic ultrasound gallbladder drainage with a lumen-apposing metal stent versus percutaneous transhepatic gallbladder drainage for acute cholecystitis. Clin Gastroenterol Hepatol 2017; 15: 738 - 745

[7] Teoh AYB, Serna C, Penas I et al. Endoscopic ultrasound-guided gallbladder drainage reduces adverse events compared with percutaneous cholecystostomy in patients who are unfit for cholecystectomy. Endoscopy 2017; 49: $130-138$

[8] Anderloni A, Buda A, Vieceli F et al. Endoscopic ultrasound-guided transmural stenting for gallbladder drainage in high-risk patients with acute cholecystitis: a systematic review and pooled analysis. Surg Endosc 2016; 30: $5200-5208$

[9] Yokoe M, Hata J, Takada T et al. Tokyo Guidelines 2018: diagnostic criteria and severity grading of acute cholecystitis (with videos). J Hepato-biliary-pancreatic Sci 2018; 25: 41 - 54

[10] Mori Y, Itoi T, Baron TH et al. Tokyo Guidelines 2018: management strategies for gallbladder drainage in patients with acute cholecystitis (with videos). J Hepato-biliary-pancreatic Sci 2018; 25: 87 - 95
[11] Turrentine FE, Wang H, Simpson VB et al. Surgical risk factors, morbidity, and mortality in elderly patients. J Am Coll Surg 2006; 203: $865-877$

[12] Yi NJ, Han HS, Min SK. The safety of a laparoscopic cholecystectomy in acute cholecystitis in high-risk patients older than sixty with stratification based on ASA score. Minim Invasive Ther Allied Technol 2006; 15: $159-164$

[13] Charlson M, Szatrowski TP, Peterson J et al. Validation of a combined comorbidity index. J Clin Epidemiol 1994; 47: 1245-1251

[14] Yates JW, Chalmer B, McKegney FP. Evaluation of patients with advanced cancer using the Karnofsky performance status. Cancer 1980; 45: $2220-2224$

[15] Law R, Grimm IS, Stavas JM et al. Conversion of percutaneous cholecystostomy to internal transmural gallbladder drainage using an endoscopic ultrasound-guided, lumen-apposing metal stent. Clin Gastroenterol Hepatol 2016; 14: 476-480

[16] de la Serna-Higuera C, Perez-Miranda M, Gil-Simon P et al. EUS-guided transenteric gallbladder drainage with a new fistula-forming, lumenapposing metal stent. Gastrointest Endosc 2013; 77: 303-308

[17] Choi JH, Lee SS, Choi JH et al. Long-term outcomes after endoscopic ultrasonography-guided gallbladder drainage for acute cholecystitis. Endosc 2014; 46: $656-661$

[18] Ge N, Sun S, Sun S et al. Endoscopic ultrasound-assisted transmural cholecystoduodenostomy or cholecystogastrostomy as a bridge for per-oral cholecystoscopy therapy using double-flanged fully covered metal stent. BMC Gastroenterol 2016; 16: 9

[19] Jang JW, Lee SS, Park DH et al. Feasibility and safety of EUS-guided transgastric/transduodenal gallbladder drainage with single-step placement of a modified covered self-expandable metal stent in patients unsuitable for cholecystectomy. Gastrointest Endosc 2011; 74: $176-181$

[20] Ge N, Sun S, Sun S et al. Endoscopic ultrasound-assisted transmural cholecystoduodenostomy or cholecystogastrostomy as a bridge for per-oral cholecystoscopy therapy using double-flanged fully covered metal stent. BMC Gastroenterol 2016; 16: 9

[21] Itoi T, Binmoeller KF, Shah J et al. Clinical evaluation of a novel lumenapposing metal stent for endosonography-guided pancreatic pseudocyst and gallbladder drainage (with videos). Gastrointest Endosc 2012; 75: 870-876

[22] Walter D, Teoh AY, Itoi T et al. EUS-guided gall bladder drainage with a lumen-apposing metal stent: a prospective long-term evaluation. Gut 2016; 65: 6-8

[23] Lee SS, Park DH, Hwang CY et al. EUS-guided transmural cholecystostomy as rescue management for acute cholecystitis in elderly or high-risk patients: a prospective feasibility study. Gastrointest Endosc 2007; 66: $1008-1012$

[24] Dollhopf M, Larghi A, Will U et al. EUS-guided gallbladder drainage in patients with acute cholecystitis and high surgical risk using an electrocautery-enhanced lumen-apposing metal stent device. Gastrointest Endosc 2017; 86: 636-643

[25] Irani S, Baron TH, Grimm IS et al. EUS-guided gallbladder drainage with a lumen-apposing metal stent (with video). Gastrointest Endosc 2015; 82: $1110-1115$

[26] Chan SM, Teoh AYB, Yip HC et al. Feasibility of per-oral cholecystoscopy and advanced gallbladder interventions after EUS-guided gallbladder stenting (with video). Gastrointest Endosc 2017; 85: 1225 1232

[27] Cotton PB, Eisen GM, Aabakken L et al. A lexicon for endoscopic adverse events: report of an ASGE workshop. Gastrointest Endosc 2010; 71: $446-454$

[28] Harewood GC, Wright CA, Baron TH. Impact on patient outcomes of experience in the performance of endoscopic pancreatic fluid collection drainage. Gastrointest Endosc 2003; 58: 230-235 
[29] Varadarajulu S, Tamhane A, Blakely J. Graded dilation technique for EUS-guided drainage of peripancreatic fluid collections: an assessment of outcomes and complications and technical proficiency (with video). Gastrointest Endosc 2008; 68: 656- 666
[30] Teoh AYB, Dhir V, Kida M et al. Consensus guidelines on the optimal management in interventional EUS procedures: results from the Asian EUS group RAND/UCLA expert panel. Gut 2018; 67: 1209-1228

[31] Kahaleh M, Perez-Miranda M, Artifon EL et al. International collaborative study on EUS-guided gallbladder drainage: Are we ready for prime time? Dig Liver Dis 2016; 48: 1054 - 1057 
- Supplementary Table 1 Types of 30-day adverse events after EGBD.

\begin{tabular}{|l|c|}
\hline Types of adverse events & $\begin{array}{c}\text { Number of patients } \\
\mathbf{N}=\mathbf{5 8}\end{array}$ \\
\hline Procedure-related & Total=20 \\
\hline Stent obstruction & 3 \\
\hline Stent migration & 3 \\
\hline Bile leak & 3 \\
\hline Duodenal perforation & 2 \\
\hline Pneumoperitoneum & 2 \\
\hline Gastric outlet obstruction from stent & 1 \\
\hline Bleeding from puncture site & 1 \\
\hline Infected abdominal collection & 1 \\
\hline Bleeding in gallbladder & 1 \\
\hline Bleeding from cystic artery & 1 \\
\hline Infected ascites & 1 \\
\hline Procedure-unrelated & Total=39 \\
\hline Sepsis with organ failure & 12 \\
\hline Peptic ulcers with bleeding (away from & 5 \\
\hline the puncture site) & 3 \\
\hline Pneumonia & 2 \\
\hline Congestive heart failure & 10 \\
\hline Decompensated liver cirrhosis & 3 \\
\hline Acute coronary syndrome & 30 -day adverse event. \\
\hline Atrial fibrillation & \\
\hline Acute renal failure & 3 \\
\hline Miscellaneous & 2 \\
\hline Please note that some patients had more than on & \\
\hline
\end{tabular}

- Supplementary Table 2 Comparison of outcomes between different stent systems.

\begin{tabular}{|c|c|c|c|c|c|}
\hline & $\begin{array}{l}\text { AXIOS } \\
N=285\end{array}$ & $\begin{array}{l}\text { Spaxus } \\
\mathrm{N}=9\end{array}$ & $\begin{array}{l}\text { Bona - AL } \\
N=56\end{array}$ & $\begin{array}{l}\text { Microtech } \\
N=29\end{array}$ & $P$ value \\
\hline Technical success (\%) & $95.8 \%$ & $100 \%$ & $96.4 \%$ & $86.2 \%$ & 0.109 \\
\hline Clinical success (\%) & $89.8 \%$ & $100 \%$ & $94.6 \%$ & $89.7 \%$ & 0.520 \\
\hline Unplanned procedural events (\%) & $8.4 \%$ & $0 \%$ & $7.1 \%$ & $24.1 \%$ & $0.028^{1}$ \\
\hline Endoscopist experience <25 (\%) & $46 \%$ & $100 \%$ & $10.7 \%$ & $86.2 \%$ & $<0.001^{1}$ \\
\hline 30-day adverse events (\%) & $18.2 \%$ & $11.1 \%$ & $7.1 \%$ & $3.4 \%$ & $0.045^{1}$ \\
\hline 30-day mortality (\%) & $11.1 \%$ & $11.1 \%$ & $1.8 \%$ & $3.4 \%$ & 0.100 \\
\hline
\end{tabular}

